\title{
Design and Development of an E-Learning Environment for the Course of Electrical Circuit Analysis
}

\author{
Omer Deperlioglu \\ Afyon Kocatepe University, \\ Afyonkarahisar, Turkey \\ odeper@aku.edu.tr
}

\author{
Utku Kose \\ Usak University, \\ Usak, Turkey
}

utku.kose@usak.edu.tr

\section{Ramazan Yildirim \\ Uşak Provincial Directorate for National Education, Turkey \\ ramazanyildirim64@gmail.com}

\begin{abstract}
E-learning is an educational approach that combines different types of multimedia technologies to ensure better education experiences for students and teachers. Today, it is a popular approach among especially teachers and educators. In this sense, this paper describes a web based elearning system that was designed and developed to be used in the "Electrical Circuit Analysis" course of electrical engineering education given at Afyon Kocatepe University. The developed system includes many lesson content pages that include content texts and some interactive simulations designed with Flash technology. Furthermore, the system also employs some online communication and assessment tools developed for teachers and students. In order to evaluate its effectiveness, the system was actively used within an experimental evaluation process. According to the obtained results, the developed system improves students' achievements on the course of Electrical Circuit Analysis and provides an effective way in engineering education.
\end{abstract}

Keywords: E-learning; web based education system; interactive learning environments; interactive simulations; blended learning

\section{Introduction}

The e-learning method allows teachers and educators to provide educational materials and the related knowledge to a wide-range of learners by using more effective and efficient communication channels. In a typical e-learning scenario, learners are not required to attend classrooms to

Material published as part of this publication, either on-line or in print, is copyrighted by the Informing Science Institute. Permission to make digital or paper copy of part or all of these works for personal or classroom use is granted without fee provided that the copies are not made or distributed for profit or commercial advantage AND that copies 1) bear this notice in full and 2) give the full citation on the first page. It is permissible to abstract these works so long as credit is given. To copy in all other cases or to republish or to post on a server or to redistribute to lists requires specific permission and payment of a fee. Contact Publisher@InformingScience.org to request redistribution permission. follow face-to-face lecture parts of the given courses. Rather, they are enabled to join special course sessions and to establish contact with other learners or teachers via some advanced tools. All of these activities are performed with the support of the conventional or modern telecommunication infrastructure (Kambourakis, Kontoni, Rouskas, \& Gritza, 2007). 
The use of computer and Internet technologies enables educators and learners to take advantage of e-learning systems from all over the world. So, enormous research efforts have been made to design and develop different types of e-learning systems, especially during the last few years (Takahama et al., 2005). As a result of rapid improvements in both computer and Internet technologies, features and functions of e-learning systems have been improved. It has also become easier to access online lesson content and interactive, electronic applications or tools from anywhere, at anytime. At this point, internet and the related technologies have an important role to play in all of these improvements and changes (Deperlioglu \& Kose, 2010; Jou, 2005).

Nowadays, researchers place emphasis upon, not only developing improved and effective elearning systems, but also providing more advanced and interactive e-learning environments and applications that enable teachers to make technical courses more attractive and effective for students. At this point, it is important to use more effective methods and techniques to present technical problems or complex course subjects as simply as possible. To this end, interactive animations are widely used in today's e-learning systems (Garrison \& Kanuka, 2004). Apart from interactive animations, it is also possible to develop applications that enable students to combine the skills, knowledge, and competences required in the academic and laboratory environments (Cockbain, Blyth, Bovill, \& Morss, 2009). These might be described as virtual laboratories and simulation programs that are developed for specific course subjects. Virtual laboratories and simulation programs are widely used, especially in higher education institutions, to provide the complex levels of interactivity needed by students (Pivic, 2007; Pulman, Scammell, \& Martin, 2009; Yang \& Liu, 2007). In addition to virtual laboratories and simulation programs, there are also many different e-learning applications and systems that were introduced in the literature and developed for specific course subjects by using well-known programming and development environments like Java $^{\mathrm{TM}}$, Macromedia Shockwave ${ }^{\mathrm{TM}}$ and Macromedia Director ${ }^{\mathrm{TM}}$ (Drofenik, Kolar, van Duijsen, \& Bauer; 2001; Gilbert, Wang, \& Sim, 2005; Lazaridis, Paparrizos, Samaras, \& Sifaleras, 2007; Méndez, Lorenzo, Acosta, Torres, \& González, 2006; Ong, 2006; Toral, Barrero, MartínezTorres, \& Gallardo, 2007).

In order to provide effective e-learning experiences for students, it is also important to consider two different aspects of e-learning systems and applications: firstly, the e-learning activity platform, which is a complex environment with a number of integrated tools for teaching, learning, communicating and managing lesson contents or materials, and secondly, the didactic module, which is the educational content provided through the related activity platform (Costabile, Lanzilotti, Plantamura, \& Roselli, 2005). At this point, ensuring harmony between activity platform and the didactic module is an important aspect of system design.

This paper describes a web based e-learning system that was designed and developed to be used in the "Electrical Circuit Analysis" course of electrical engineering education given at Afyon Kocatepe University, Turkey. The system is currently used within a mixed learning model that was designed and developed to be used for electrical engineering courses given at the Afyon Kocatepe University. At this point, a blended learning approach is used, which employs different types of learning and teaching methods for different in education processes. In this way, advantages of different education methods are combined in a single model. A community of learning and investigation is also facilitated by encouraging discussion, debate, and negotiation, which are known as attributes of higher education (Garrison \& Kanuka, 2004).

The rest of the paper is structured as follows.

- The second section describes the main structure and some basic features of the e-learning system. 
- The third section explains how to use the features of the e-learning interfaces and tools. In this way, educational activities that can be performed on the system are also described briefly.

- The fourth section is devoted to the experiment process, which were performed to evaluate effectiveness of the system.

- The fifth section outlines the conclusions that have been reached with the study and explains some future works.

\section{A Web Based E-Learning System for Electrical Circuit Analysis Course}

The system that was developed in this study provides an effective and efficient web platform where students and teachers can use different educational tools to perform related learning and teaching activities in the Electrical Circuit Analysis course. In order to ensure an effective educational environment, the system has been designed and developed with the support of different technologies. It is also important that both database (table groups associated with different sections of the system) and interface (page groups associated with different features and functions of the system) parts of the system have been formed on a structural scheme. The structure of the system is described below.

\section{Main Structure of the Developed System}

The system consists of two different parts: the "database system" and the "web platform system". The database system employs three database files, which were designed and developed using Microsoft Access $^{\mathrm{TM}}$. Each database file is related to a different part of the system. One of these files is used to store information about system users (administrators, students, and teachers), main system features or functions, and some specific system tools. Another database file is used to store information about related adjustments for assessment tools provided within the system. Questions for system tests and exercises are also stored in this database. The final database file is used to store lesson contents that were added by teachers to the system. The whole database system is connected to the web platform system using various database functions. Figure 1 shows a brief overview of the database system.
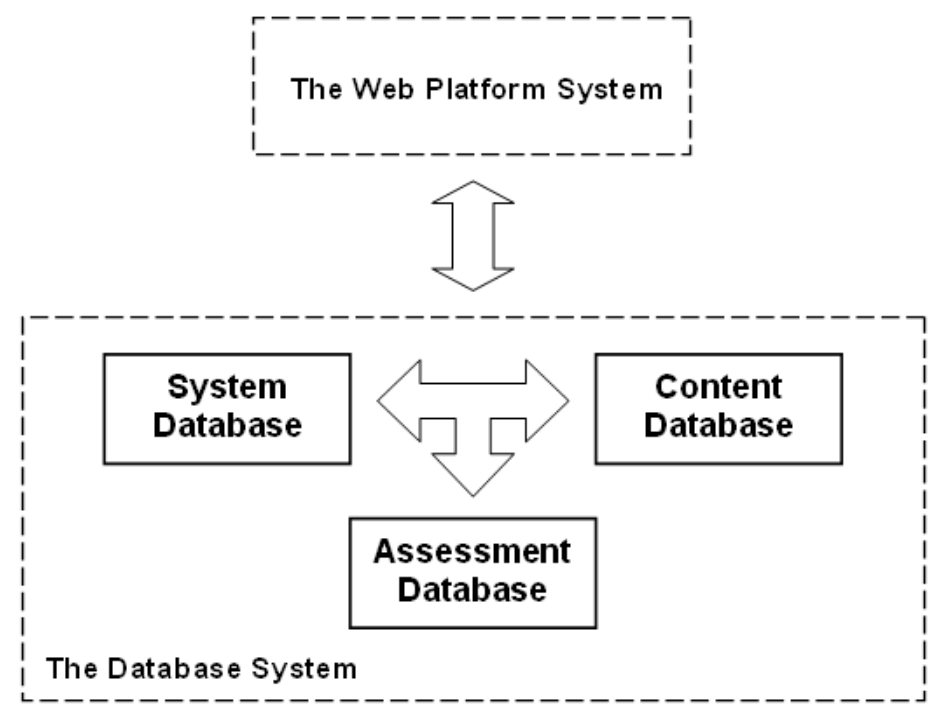

Figure 1. A brief overview of the database system 
The web platform system corresponds to web interfaces and tools that are included in the system and provided to administrators, students, or teachers according to their activities in connection with the system. There are three different types of user: administrators, students, and teachers. In order to log into the system, all of these users must type their usernames and passwords on the login page of the system. After logging into the system, administrators can use different management tools to adjust main system features and edit other users' (students and teachers) personal information.

Students and teachers, on the other hand, can use educational tools to perform their own activities on the system.

- Students can use the related tools to view course lesson contents, study on simulations or animations, and perform other learning activities.

- Teachers can adjust features and functions of the educational tools and manage learning activities that are performed by students.

The system provides similar web interfaces for each user type and enables all users to perform their activities easily with the support of simple, fast and interactive features and functions. Figure 2 shows a brief overview of the web platform system.

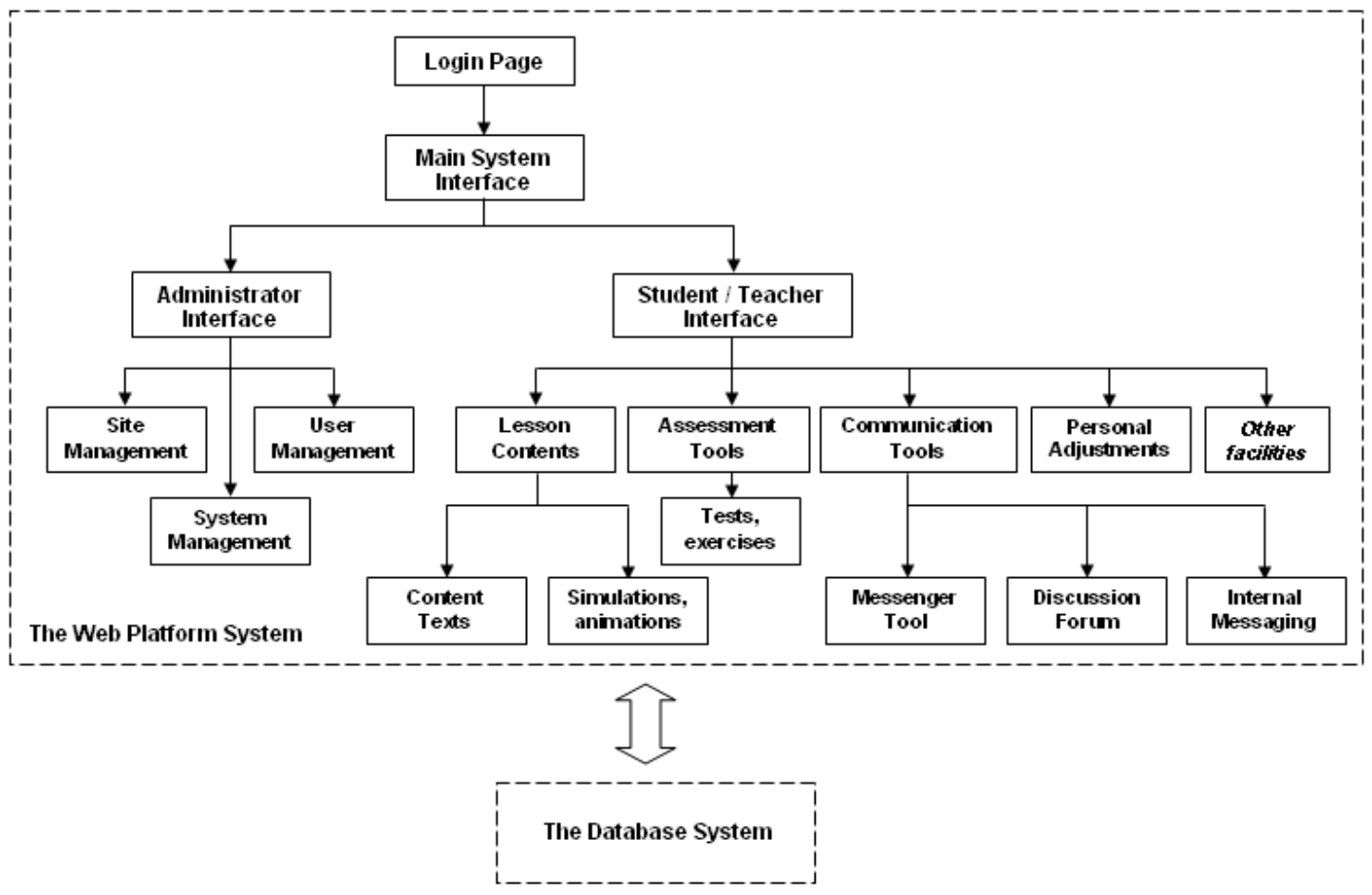

Figure 2. A brief overview of the web platform system

A typical online learning process is planned on the system according to students' and teachers' needs during the course.

\section{Educational Activities with the Developed Web Based E-Learning System}

The system provides an interactive, simple, and fast interface, which can be used easily by both students and teachers. The main system interface and educational tools are designed and developed by using $\mathrm{ASP}^{\mathrm{TM}}$ (Active Server Page) technology. In this way, an interactive web environ- 
ment, which can perform different system functions according to students' and teachers' requests, is ensured. Currently, the developed web based e-learning system is provided under a LMS (learning management system) named @KU-UZEM. The related LMS is used for both hosting and facilitating the course management. This LMS is hosted at the url: www.uzem.aku.edu.tr

\section{Main System Interface}

The main system interface is the web page that is viewed for each student and teacher after the login process. Both students and teachers can use this interface to reach all system tools and perform related activities. Figure 3 shows a screenshot from the main system interface.

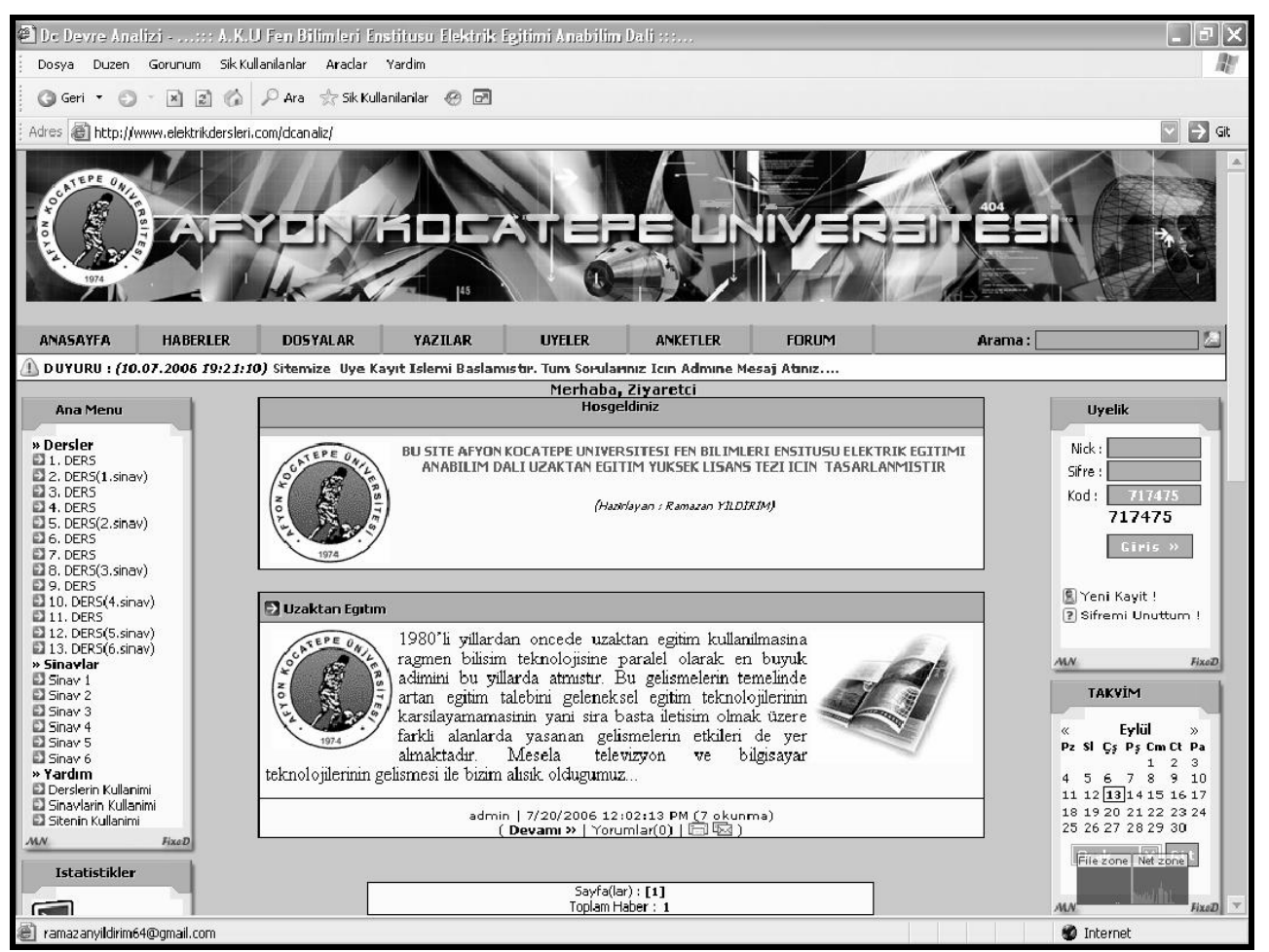

Figure 3. A screenshot from the main system interface

The main system interface includes four different panels that direct students and teachers to different parts of the system. There are two tool panels located at either side of the interface. The first of these provides some links for stored course lesson contents, active tests or exercises, and related system help pages. After the login process, students can use these links to view lesson contents, tests, or exercises immediately. Additionally, some statistical information about online users, stored lesson contents, files, etc. is viewed on this panel. The second tool panel includes some links and controls for different system tools provided for students and teachers. Controls and links included in this panel are automatically changed according to the user type as student or teacher. By default, both students and teachers can use some communication tools via this panel. Additionally, there are also some extra tools (calendar, personal diary) provided. This panel also allows teachers to use a small login tool to open more detailed management interface.

The third panel, which is located on the middle of the main system interface, is called the "Activity Panel". The Activity Panel is used to view interfaces of some specific system tools. After clicking on links of the related system tools, interfaces of these tools are automatically viewed on the Activity Panel. By default, system announcements and news are viewed on this panel. The last panel, which is also called "Link Bar", is located on top of the other panels; it employs some 
links related to different system tools. There is also a "search box", which can be used by students and teachers to search a word in the stored course lesson contents.

\section{Management Interfaces}

The system provides a detailed management interface that can be used by teachers to arrange and control online learning activities, manage course lesson contents, and adjust some specific features and functions of the educational tools. As mentioned before, this interface can be viewed by using the small login tool that is provided on the right tool panel of the main system interface. The management interface has been designed as similar to a typical admin panel. Thus, it comes with a simple and fast interface.

In the related interface, management activities are provided in separate panels that correspond to options of different educational tools and system functions. After clicking on any link, the corresponding management page is automatically viewed in the right side of the management interface.

In addition to the management interface, which was developed to be used by teachers, the system also includes another management interface that is used by only system administrators. After the login process, the system automatically directs administrators to this management interface - also called the "Admin Panel". The Admin Panel has been developed with almost same design with the other management interface that is used by teachers. But it includes more options and management tools to adjust main system features and edit other users' (students and teachers) personal information. On the Admin Panel, it is also possible to view some statistical information about system users, lesson contents, stored files, and some specific features or functions of the system. By using the related options, administrators can also control learning activities and manage course lesson contents.

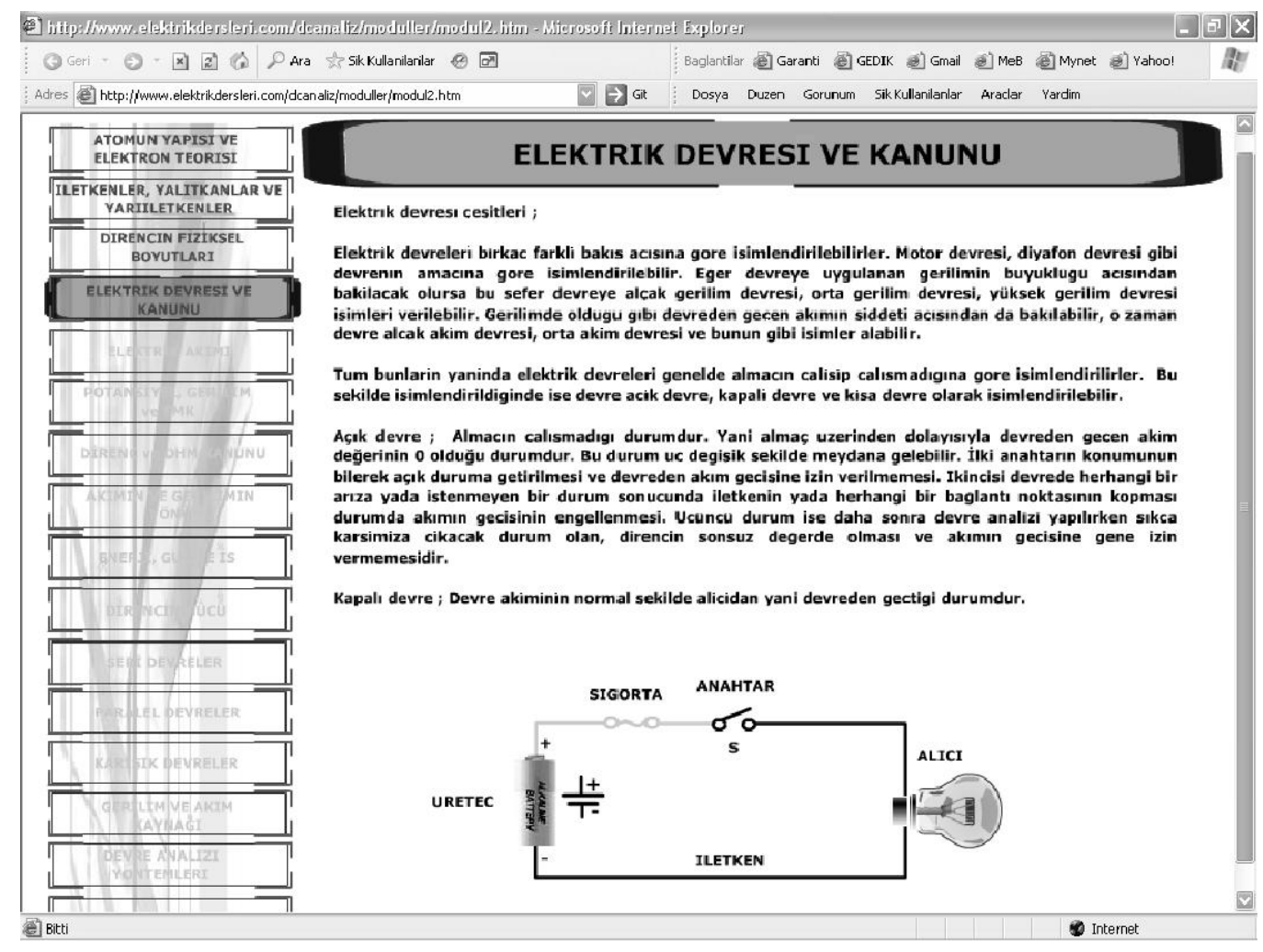

Figure 4. A screenshot from a sample content page 


\section{Course Lesson Contents and Interactive Simulations}

In order to provide an effective and attractive online learning experience, the system provides visual and interactive lesson contents for the Electrical Circuit Analysis course. It is important to use more effective methods and techniques to enable students to understand and learn technical problems or complex subjects that are provided within a typical course. For this reason, course lesson content has been supported with Flash ${ }^{\mathrm{TM}}$ based simulations and animations. In addition to these elements, each course subject is also explained with simple and intelligible sentences. All course lesson contents can be viewed easily by clicking on the links provided on the left tool panel of the main system interface. Figure 4 shows a screenshot from a sample content page.

In the system, there are many different simulations and animations that are included within the provided course subjects. Animations are used to explain important subjects in dynamic and colourful scenes that are prepared using Flash ${ }^{\mathrm{TM}}$ technology. It is important that each animation corresponds to a particular lesson content text, which it explains with the help of different visual methods and techniques. Simulations are used to ensure highly interactive learning environments, which enable students to make different types of experiments, examine dynamic events, and evaluate results with the support of virtual tools. Eventually, students can understand and learn by using all of these objects included in course lesson contents of the system. It is also extremely important to note that many of these simulations enable students to perform more complex and advanced experiments than could be performed via mechanic experiment sets. This enables teachers to achieve their teaching goals easier and faster. Figure 5 shows some simulations provided in the system.
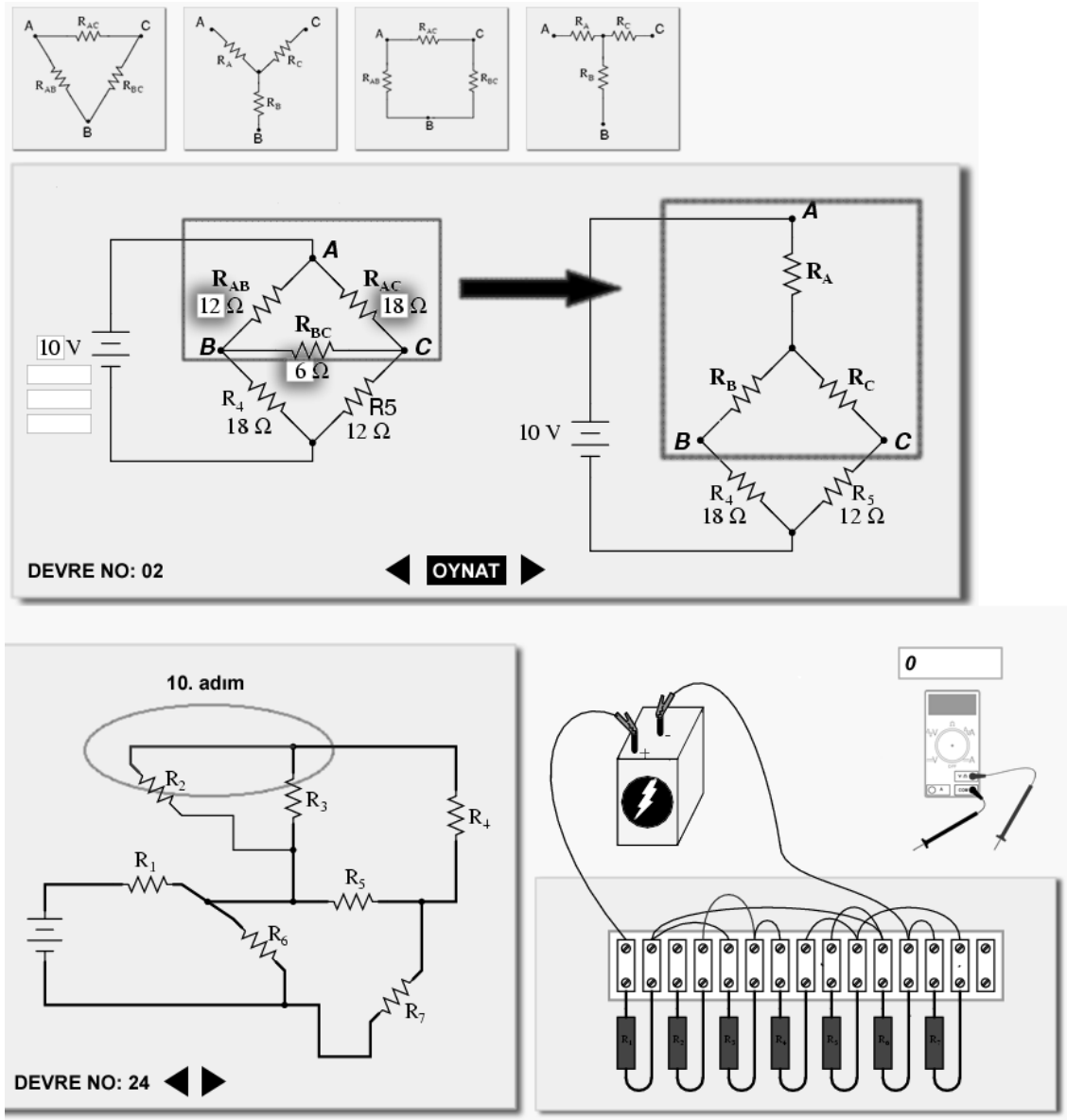

Figure 5. Some simulations provided in the system 
Teachers can use the management interface to manage course lesson content. By using the related options, it is possible for teachers to edit any lesson content easily. By default, the Electrical Circuit Analysis course is provided with thirteen subject titles. But it is also possible to add new lesson content subjects to the system by using the related options on the management interface. The system employs a rich text editor that allows teachers to write and format content text and upload images or Flash ${ }^{\mathrm{TM}}$ objects to the content environment. Any stored content can also be edited by using this editor. For each item of lesson content, teachers can define a time period in which the content will be active to be viewed by students. It is also possible for teachers to associate any content with active test or exercises stored in the system. In this way, the students are not allowed to view new lesson contents without finishing the related tests or exercises.

\section{Communication Tools}

The system employs three different communication tools that can be used to ensure communication function among system users. Both students and teachers can start to use communication tools immediately with the help of provided links or controls on the right tool panel of the main system interface. All of these communication tools aim to improve the quality of the education activities by ensuring effective socialization processes among students and teachers.

- The first communication tool is a messenger application that can be used to make text based chat with other online users. It provides an interactive interface, where the user can see a list of online users. Upon clicking on any username, a chat session is immediately started. By using the related controls, it is possible to adjust user state as "online" or "offline".

- The second communication tool is a forum tool, which is used to post new personal messages or make comments on existing ones. Forum titles provided for students may only be defined by teachers via the management interface. Discussions that are performed on the forum tool may also be moderated by teachers.

- The final communication tool of the system is an internal messaging tool, which allows students and teachers to send private messages to other users by using the system infrastructure.

\section{Assessment Tools}

Within the system, it is possible for students to check their own learning and knowledge levels by taking tests and exercises. Active tests and exercises are listed for students on the left tool panel of the main system interface. Students can take any test or exercise by clicking on the related link. In the system, a typical test includes 25 questions and allows students to finish test in 30 or 35 minutes. On the other hand, exercises are provided with 10 questions and have no time limitation. Figure 6 shows a screenshot from the test page.

At the end of each test and exercise, students are informed about their correct and incorrect answers and also gained total points. At this point, each student's test and exercise results are stored in the system database. Thus, teachers can examine and evaluate test and exercise results via management interface.

By using the management interface, teachers are enabled to create new tests or exercises and prepare their own questions to be stored in the system database. The system provides a rich text editor, which can be used by teachers to prepare visual and specially formatted test or exercise questions. It is also possible for teachers to prepare and store questions for future use. In the system, five possible answers can be defined for each question. After determining the appropriate questions, a test or exercise can be created by using the related options and controls. For each test or 
exercise teachers can define a time period in which the created test or exercise will be active for students. System link of each new test and exercise is automatically added to the related tool panel, by the system.

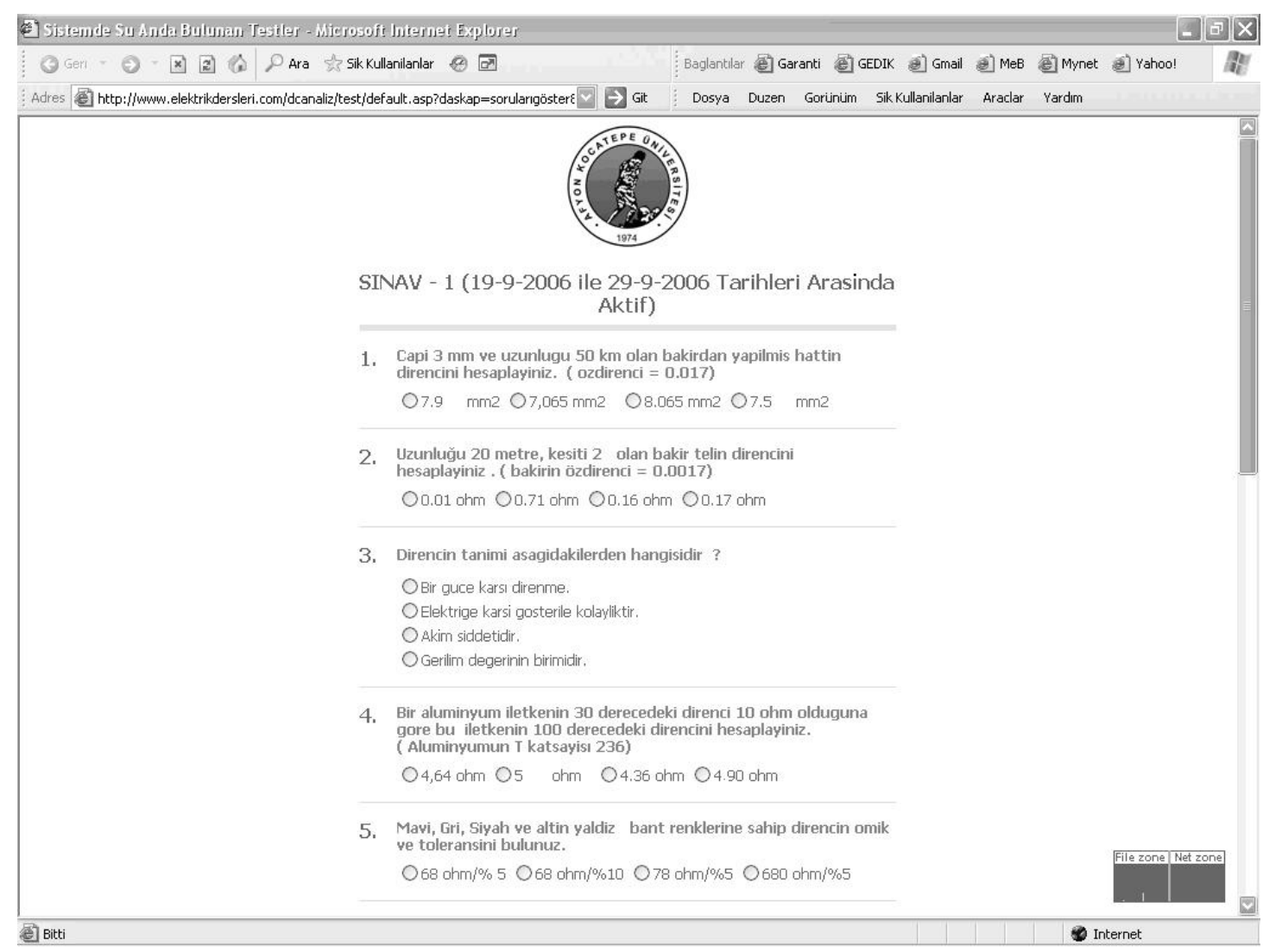

Figure 6. A screenshot from the test page

\section{Evaluation}

In order to evaluate the effectiveness of the e-learning system, an experiment, which was formed with an experimental group who used the system in the related learning activities and a control group who participated only in a face-to-face education process, was performed during the Electrical Circuit Analysis course. Additionally, the students who participated in the experimental group were asked to write down their comments about features and functions of the system. These helped the authors in deciding how to continue the development of the web based elearning system.

\section{Experimental Evaluation and Obtained Results}

During the experimental evaluation, 50 students comprised the experimental group; the control group was comprised of another group of 50 students. Thus, a total of 100 students participated in the experiment. In this context, each student's past success rates (student grades) for previously courses were used to obtain "level-headed" groups. Students at similar levels were assigned to different groups to achieve the "balance" between the related groups. Thus, it was assured that the groups were matched before the experimental evaluation process. On the other hand, during the experimental evaluation process, the related learning-teaching activities explained below were performed for the experimental and the control group: 
- The experimental group used the Web Based E-Learning system with its all features and functions (interactive interfaces, the related course contents, tests, Flash simulations, etc.) in the related learning activities.

- The control group used only some mechanical experiment sets provided by the teacher.

- For both groups, a total of 14 weeks lecture hours (4 hours for each week) were organized within one term. The related learning-teaching activities were performed for each group, in separately set course laboratories. In this context, the related tutoring supports were also given to the related groups. Additionally, support on usage of the Web Based E-Learning system was also given to the experimental group students.

At the end of the Electrical Circuit Analysis course, students' grades (on the scale of 100) were considered for the experimental evaluation. Table 1 below shows the obtained results for both experimental and control groups.

Table 1. Obtained results for experimental and control groups

\begin{tabular}{|l|l|l|l|l|}
\hline & $\begin{array}{c}\text { Students who passed } \\
\text { the course (\%)* }\end{array}$ & Mean & St dev. & Median \\
\hline Control group (50 students) & $44 \%$ & 51,93 & 12,27 & 54,3 \\
\hline Experimental group (50 students) & $74 \%$ & 74,82 & 16,95 & 80,2 \\
\hline
\end{tabular}

As it can be seen in Table 1, the percentage of the students who passed the given Electrical Circuit Analysis course is significantly high in the experimental group. The mean "student grade" of the experimental group is also higher than the value of the control group. As a result, experimental evaluation results show an improved student achievement and learning level after using the developed web based e-learning system. It is concluded that, the system provides effective and efficient approaches and methods for electrical engineering education. Figure 7 represents a graph that shows the number of control and experimental group students in different grade ranges.

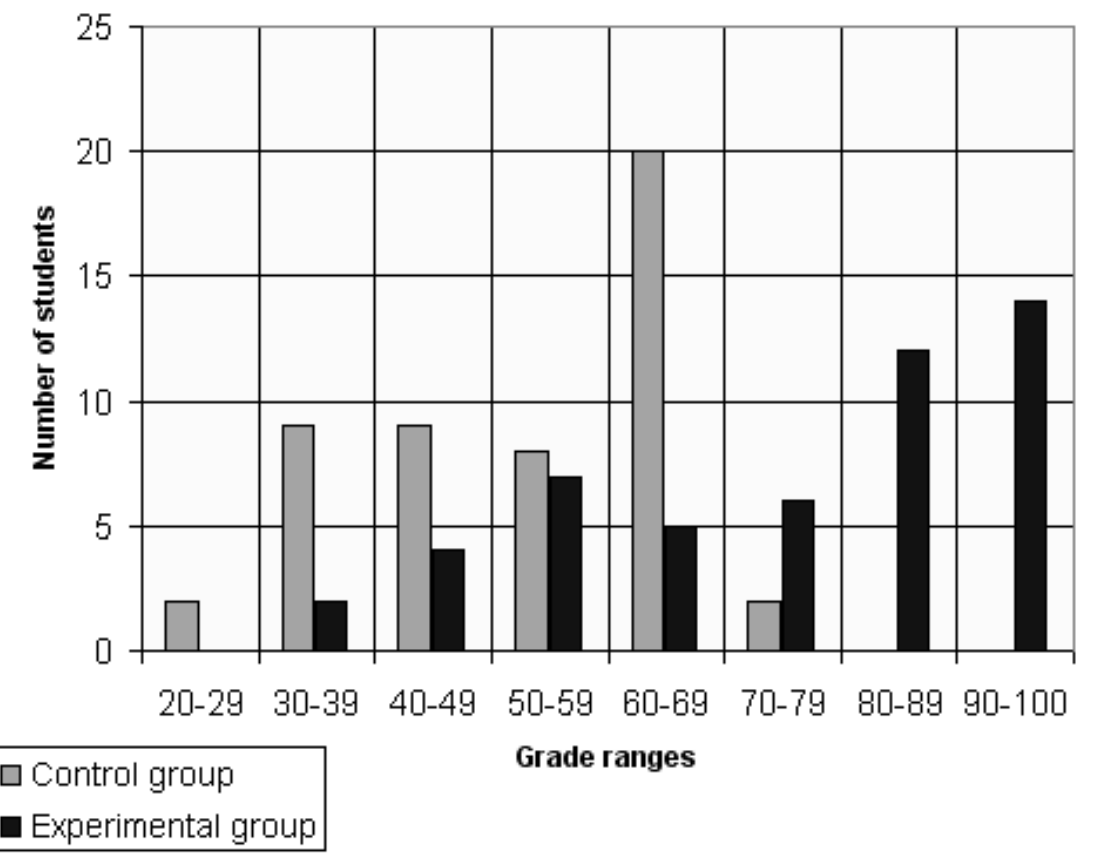

Figure 7. Number of control and experimental group students in different grade ranges 
A statistical analysis was carried out to understand if the obtained results between the control and the experimental group grades were similar or not. In order to achieve this, an "independent samples t-test" was performed. Results suggest that the alternative hypothesis $\left(\mathrm{H}_{1}\right)$, which states that the means of the two samples are different, cannot be rejected (with $95 \%$ confidence).

\section{Student Comments about the Developed System}

At the end of the course, students in the experimental group wrote down their comments about features and functions of the system. The most remarkable and interesting comments are listed below:

- "The developed system includes effective simulations and animations that enable me to understand given course subjects easily."

- "As a result of using this system, my academic achievement has improved."

- "I liked the online learning process, which was performed via this system."

- "With the support of this system, fundamentals of electrical circuit analysis can be learned better."

- "This system provides a simple and fast interface."

- "I can not adjust visual features of the system according to my choice. There should be additional system tools that enable me to adjust some visual features of the system."

- "There should be more interactive communication tools like video conferencing in the system."

- "The system should be adapted to other electrical engineering courses."

\section{Conclusions and Future Work}

This paper describes a web based e-learning system that was designed and developed to be used in the "Electrical Circuit Analysis" course of electrical engineering education given at Afyon Kocatepe University, Turkey. The system aims to provide an effective and efficient way of teaching electrical circuit analysis, which is an important subject of the electrical engineering course.

Obtained results show that the system has provided an effective and efficient education process for the Electrical Circuit Analysis course. As a result of using the system in learning activities, students' academic achievements and also learning levels were improved greatly. Students were also satisfied with the system and performed online learning activities. According to students, interactive features and functions of the system allowed them to learn technical and complex course subjects better. Students also think that the provided simulations and animations played an important role in enabling them to learn course subjects easily.

Positive results have encouraged authors to think about some future work and continue development of the web based e-learning system. In this sense, the system will be adapted and used in other electrical engineering courses given at the Afyon Kocatepe University. In order to use the system in different courses, some features and functions of the system will be improved and more educational tools will be integrated to the system interface. At this point, students' comments about the system have an important role on this development. In the future, it is also possible to use the system in some master degree electric education courses.

Further future work will include the development of an interactive virtual laboratory application. With this application, both students and teachers will have a chance to prepare their own electri- 
cal circuits and work on them by using some application tools. In this way, it will be possible to perform most of electrical experiments that are provided within the electrical engineering courses.

\section{References}

Cockbain, M. M., Blyth, C. M., Bovill, C., \& Morss, K. (2009). Adopting a blended approach to learning: experiences from radiography at Queen Margaret University, Edinburgh. Radiography, 15(3), 242246.

Costabile, M. D., Lanzilotti, R., Plantamura, V. L., \& Roselli, T. (2005). On the usability evaluation of elearning applications. HICSS '05, Proceedings of the $38^{\text {th }}$ Hawaii International Conference on System Sciences, 1, 1-10.

Deperlioglu, O., \& Kose, U. (2010). The effectiveness and experiences of blended learning approaches to computer programming education. Computer Applications in Engineering Education [in Early View]. DOI: $10.1002 /$ cae. 20476

Drofenik, U., Kolar, J. W., van Duijsen, P. J., \& Bauer, P. (2001). New web-based interactive e-learning in power electronics and electrical machines. Thirty-Sixth IAS Annual Meeting, Industry Applications Conference, 3, 1858 - 1865.

Garrison, R. D., \& Kanuka, H. (2004). Blended learning: Uncovering its transformative potential in higher education. The Internet and Higher Education, 7, 95-105.

Gilbert, L., Wang, C., \& Sim, Y.-W. (2005). An e-learning systems engineering methodology. ICALT 2005, Fifth IEEE International Conference on Advanced Learning Technologies, 150 - 154.

Jou, M. (2005). Development of an e-learning system for teaching machining technology. AMT 2005 International Conference on Active Media Technology, 347 - 352.

Kambourakis, G., Kontoni, D.P.N., Rouskas, A., \& Gritza, S. (2007). A PKI approach for deploying modern secure distributed e-learning and m-learning environments. Computers \& Education, 48(1), 1-16.

Lazaridis, V., Paparrizos, K., Samaras, N., \& Sifaleras, A. (2007). Visual LinProg: A web-based educational software for linear programming. Computer Applications in Engineering Education, 15(1), 1-14.

Méndez, J. A., Lorenzo, C., Acosta, L., Torres, S., \& González, E. (2006). A web-based tool for control engineering teaching. Computer Applications in Engineering Education, 14(3), 178-187.

Ong, S. K. (2006). Development of a web-based graduate-level module courseware. Computer Applications in Engineering Education, 14(2), 90-105.

Pivic, M., (2007). Editorial. Play and learn: Potentials of game-based learning. British Journal of Educational Technology, 38(3), 387-393.

Pulman, A., Scammell, J., \& Martin, M. (2009). Enabling interprofessional education: The role of technology to enhance learning. Nurse Education Today, 29(2), 232-239.

Takahama, S., Nakamura, N., Barolli, L., Koyama, A., Durresi, A., \& Sugita, K. (2005). An e-learning system for improving learner study efficiency by stimulating learner volition. $11^{\text {th }}$ International Conference on Parallel and Distributed Systems, (ICPADS'05), 05/5.

Toral, S. L., Barrero, F., Martínez-Torres, M. R., \& Gallardo, S. (2007). Interactive multimedia teaching of digital signal processors. Computer Applications in Engineering Education, 15(1), 88-98.

Yang, Z., \& Liu, Q. (2007). Research and development of web-based virtual online classroom. Computers \& Education, 48(2), 171-184. 


\section{Biographies}

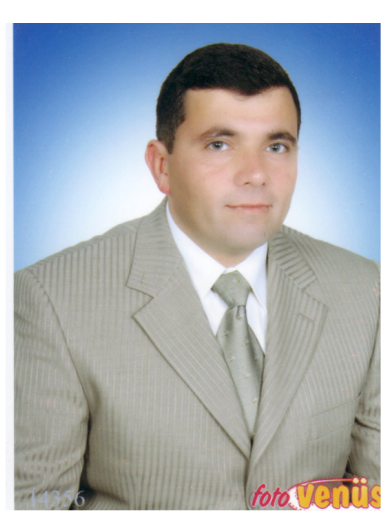

Omer Deperlioglu received the B.S. degree in 1988 from the electrical education of Gazi University, in Turkey. He received M.S. degree in 1996 from Afyon Kocatepe University, Turkey, and he completed his Ph. D. degree in 2001 at Gazi University in field of controlling switch-mode dc-dc converters with neuro-fuzzy system.

He is currently an Associate Professor in Afyon Kocatepe University, Turkey. His research interest includes computer-based control systems, fuzzy logic control, neuro-fuzzy control and distance learning.

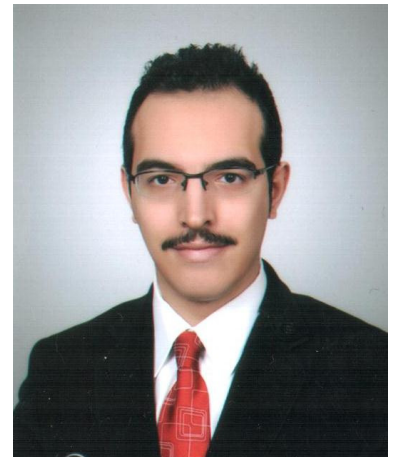

Utku Kose received the B.S. degree in 2008 from Computer Education of Gazi University, Turkey, as a faculty valedictorian. He received M.S. degree in 2010 from Afyon Kocatepe University, Turkey, and now he continues D.S. / Ph. D. at Selcuk University, Turkey, in the field of computer engineering. Between 2009 and 2011 he has worked as a Research Assistant in Afyon Kocatepe University. Following, he has also worked as a Lecturer and Vocational School - Vice Director in Afyon Kocatepe University between 2011 and 2012.

Currently, he is a Lecturer in Usak University, Turkey. His research interest includes artificial intelligence, the chaos theory, distance education, computer education, online / virtual laboratories and cryptography.

Ramazan Yildirim - Ramazan Yildirim received the B.S. degree in 2004 from the Electrical Education of Firat University, Turkey. He is currently an electrical education teacher in Veyis Turan Multi-Program High School, Turkey. His research interest includes electrical education, distance learning and e-learning. 